\title{
Does contralateral carotid artery occlusion affect the clinical and long-term outcomes of carotid artery stenting?
}

Yusuf Can, Ibrahim Kocayigit

Department of Cardiology, University of Sakarya, Sakarya, Turkey

Submitted: 7 September 2019

Accepted: 2 January 2020

Arch Med Sci Atheroscler Dis 2020; 5: e13-e19

DOI: https://doi.org/10.5114/amsad.2020.92723

Copyright @ 2020 Termedia \& Banach

\begin{abstract}
Introduction: Carotid artery stenting (CAS) has been used with increasing frequency in recent years as an alternative to surgery. Contralateral carotid occlusion (CCO) is present in approximately $2.3 \%$ to $25 \%$ of cases of revascularised carotid atherosclerotic stenosis. We aimed to compare the outcomes of 30-day, 6-month and 1-year stroke, transient ischaemic attack (TIA), death and myocardial infarction (MI) in patients with and without CCO who underwent CAS in our clinic.

Material and methods: The study was conducted with 288 consecutive patients who underwent CAS between September 2010 and June 2018. Patients with carotid stenting were divided into two groups: with (48 patients) and without CCO (240 patients).

Results: Total mortality $(2.08 \%$ vs. $2.08 \% p=1)$, stroke $(2.08 \%$ vs. $0.83 \%$, $p=0.43$ ), TIA ( $0 \%$ vs. $0.83 \%, p=0.52)$, MI ( $0 \%$ vs. $0 \%$ ), and composite outcome $(4.17 \%$ vs. $3.33 \%, p=0.77)$ at 30 days were not significantly different between $\mathrm{CCO}$ and non-CCO groups. Also there was no statistically significant difference between the two groups in terms of the 6-month and 1-year outcomes $(p>0.05)$.

Conclusions: There was no difference between 30-day, 6-month and 1-year non-fatal MI, TIA, ischaemic stroke and mortality in the comparison of patients with and without CCO who underwent CAS. The outcomes were similar in terms of age and symptoms, and these data should be supported by prospective multicenter studies.
\end{abstract}

Key words: atherosclerosis, carotid artery stenting, contralateral carotid occlusion.

\section{Introduction}

Carotid artery (CA) diseases are frequently diagnosed due to the ongoing increase in average life expectancy and the widespread availability of imaging systems. Stroke is the most common cause of disability of CA diseases and ranks third in mortality [1]. About $15 \%$ to $20 \%$ of all strokes are caused by CA stenosis, and the most common location of stenosis is the margin of the proximal internal CA and common CA bifurcation [2, 3]. Although carotid artery endarterectomy (CEA) in conjunction with medical treatment is the gold standard therapy for CA stenosis, carotid artery stenting (CAS) has been used with increasing frequency in recent years as an alternative to surgery [4]. Contralateral carotid occlusion (CCO) is

\author{
Corresponding author: \\ Ibrahim Kocayigit \\ Department of Cardiology \\ University of Sakarya \\ Sakarya, Turkey \\ Phone: +90 5309323075 \\ E-mail: ikocayigit@gmail.com
}


present in approximately $2.3 \%$ to $25 \%$ of patients following revascularisation of the CA [5]. However, there is no consensus on a revascularisation strategy for CA stenosis in patients with CCO. Previous studies have shown that perioperative stroke and mortality are more common in patients with CCO following CEA $[6,7]$. Although patients with CCO and CA stenosis scheduled for CEA are considered to be at high risk [8], the impact of carotid stenting is still less understood. The outcomes of patients with CCO following carotid stenting appear to be similar to those without CCO [9].

Thus, the aim of the present study was to compare the 30-day, 6-month and 1-year outcomes of stroke, transient ischaemic attack (TIA), death and myocardial infarction (MI) of patients with and without CCO who underwent CAS in our clinic.

\section{Material and methods}

The present study included 288 patients who underwent CAS between September 2010 and June 2018. Of these patients, 48 were diagnosed with CCO (16.6\%). Patients who had an ischaemic stroke, TIA or amaurosis fugax over the last 6 months were considered symptomatic. Amaurosis fugax was defined as an isolated and transient loss of vision, TIA was defined as transient cerebral dysfunction of ischaemic origin, and stroke was defined as focal neurological deficits lasting more than $24 \mathrm{~h}$. Each patient was evaluated by at least two interventional cardiologists, and those with symptomatic > 50\% and asymptomatic $>70 \%$ common or internal CA stenosis, as determined angiographically by the North American Symptomatic Carotid Endarterectomy Trial method, were included in the study. A contralateral carotid occlusion was defined as $100 \%$ occlusion of the vessel opposite the artery undergoing carotid stenting. The exclusion criteria for the study were: acute stroke before CAS, spontaneous dissection, fibromuscular dysplasia and vasculitis. All patients were informed about the carotid stenting process and informed consent was obtained from all patients. The study was approved by the local ethics committee.

\section{Clinical evaluation and medical treatment}

All patients underwent complete pre- and postCAS neurological examinations performed by an independent neurologist. To evaluate the pre-procedural anatomies of the CAs, intracranial arteries and aortic arch, each patient underwent one or more carotid Doppler ultrasonography, cranial computed tomography angiography or magnetic resonance angiography examinations. Upon discharge, all patients were prescribed at least 4 weeks of daily clopidogrel at $75 \mathrm{mg}$ and lifetime acetylsalicylic acid at 100 mg after a 300-mg loading dose of clopidogrel.

\section{Procedure}

Cardiac activity, oxygen saturation and blood pressure were monitored during the procedure. Following local anaesthesia, an $8 \mathrm{Fr}$ introducer sheath was placed in the main femoral artery and a 5 Fr Simmons type 2 catheter or 6 Fr Judkins R 4 diagnostic catheter over a 0.035-in hydrophilic wire was placed into the common CA to allow for selective imaging of each CA. The CAs and cranial vessels were evaluated on at least two images, including lateral and anterior views. A 0.035-in hydrophilic wire was guided towards the external CA. The diagnostic catheter over the hydrophilic wire was advanced towards the external CA and the hydrophilic wire was replaced with a stiff 0.035 -in wire, which was left in the external CA, while the diagnostic catheter was removed. An 8 Fr Judkins R4 guiding catheter (Launcher, Medtronic, Inc., Minneapolis, MN, USA) was placed into the common CA and the stiff wire was removed. Intravenous heparin (5000-10,000 U) was administered, so that the average activated coagulation time would be approximately 250-300 s. Then, a distal embolic protection filter was placed in all patients (Emboshield NAV6; Abbott Laboratories, Santa Clara, CA, USA). Patients with stenosis of $\geq 90 \%$ or those with a lesion that did not allow passage for stenting underwent pre-dilatation with a 5.0 $\times$ 20-mm balloon (Viatrac 14 Plus; Guidant Corporation, Indianapolis, IN, USA). The procedure was performed with a self-expandable stent (XACT; Abbott Vascular, Galway, Ireland). Residual stenosis of $30 \%$ or less was accepted as the optimal range opening. Post-dilatation with $5 \times$ 20-mm balloons (Viatrac 14 Plus; Guidant Corporation, Indianapolis, IN, USA) was performed if an optimal range opening could not be achieved. Prior to balloon and/or stent placement, $1 \mathrm{mg}$ of atropine was intravenously administered to patients to avoid hypotension and bradycardia. At the end of the procedure, anterior-posterior and lateral cranial imaging was performed again and the procedure was terminated.

\section{Statistical analysis}

All statistical analyses were performed using SPSS Statistics for Windows, version 17.0. (SPSS Inc., Chicago, IL, USA). The normal distribution of variables was assessed using histograms and the Kolmogorov-Smirnov test. The number and percentile were used for descriptive analyses. Comparisons were made with $2 \times 2$ tables using Pearson's $\chi^{2}$ and Fisher's exact tests. Cochran's $Q$ test was used for comparisons of more than two 
variables in dependent groups. Data are expressed as mean \pm SD for parametric variables and median (minimum-maximum) for non-parametric variables. A $p$-value $<0.05$ was accepted as being statistically significant.

\section{Results}

A total of 288 patients (range 51 to 93 years) who underwent carotid stenting were divided into two groups: those with $(n=48)$ and without CCO $(n=240)$. The demographic characteristics and risk factors of the patients are shown in Table I. Of the patients who underwent CAS, 39 (81.25\%) with CCO and 195 (81.25\%) without CCO were male. There was no statistically significant difference in the gender ratio between the two groups.

Before the procedure, 37 patients diagnosed with CCO and 193 without CCO were symptomatic. Although the baseline percentage of symptomatic patients was lower in those with CCO who underwent CAS, there was no statistically significant difference between the two groups. Of all 288 patients, 16 with CCO and 86 without CCO were aged $\geq 75$ years, which was similar percentage-wise between the groups. As shown in Table II, there were no significant differences between the two groups in overall mortality $(2.08 \%$ vs. $2.08 \% ; p=1.00)$, stroke $(2.08 \%$ vs. $0.83 \%$, $p=0.43)$, TIA (0\% vs. $0.83 \%, p=0.52)$, MI (0\% vs. $0 \%)$, or composite outcome $(4.17 \%$ vs. $3.33 \%$, $p=0.77)$ at 30 days. Also there was no statistically significant difference between the two groups in terms of the 6-month and 1-year outcomes $(p>0.05)$. In patients aged $<75$ years, the incidence of stroke at 30 days, 6 months and 1 year was higher in patients with CCO than those without CCO $(p=0.028)$, while in patients aged $\geq 75$ years, the 1 -year non-cardiac mortality rate was higher in patients with CCO than those without CCO $(p=0.020)$ (Table III). Also, there was no significant difference in the presence of CCO or complication rates between symptomatic and asymptomatic patients (Table IV).

\section{Discussion}

In this study, there was no difference in 30-day, 6-month or 1-year non-fatal MI, TIA, ischaemic stroke and mortality rates between patients with and without CCO who underwent CAS. In addition, there was no significant difference in composite outcomes between symptomatic and asymptomatic patients.

The prognosis of patients with CCO following medical treatment of CA stenosis is poor, and the risk of stroke within 2 years ranges from $40 \%$ to $70 \%[6,10]$. Therefore, in addition to medical treatment, the CA of patients with CCO must be revascularised, as the risk of stroke within 1 year is about $2 \%$ in our patients with CCO who underwent CAS.

The revascularisation strategy in patients with carotid stenosis and CCO remains controversial, as there have been no prospective studies comparing the benefits of surgery versus stent placement. Previous studies and meta-analyses have shown a greater perioperative risk in patients with CCO after CEA [11-13]. The advantages of CAS include a shorter ischaemia time, lack of shunt requirement and lack of sedation/general anaesthesia requirement during the procedure. Cerebral function may be reduced during CEA due to advanced atherosclerotic disease and lack of collateral circulation in these patients. In consideration of these findings, CAS may be a good option for patients with CCO.

Table I. Comparison of demographic characteristics between patients with CCO and without CCO

\begin{tabular}{|llcl|}
\hline Parameter & With CCO & Without CCO & $P$-value \\
\hline Age [years] & $68.7 \pm 9.2$ & $71.0 \pm 8.6$ & 0.111 \\
\hline Age $\geq 75, n(\%)$ & $16(33.3)$ & $86(35.8)$ & 0.741 \\
\hline Male gender, $n$ (\%) & $39(81.2)$ & $195(81.2)$ & 1.000 \\
\hline Hypertension, $n$ (\%) & $42(87.5)$ & $183(76.2)$ & 0.085 \\
\hline Diabetes mellitus, $n(\%)$ & $22(45.8)$ & $100(41.7)$ & 0.594 \\
\hline Hyperlipidemia, $n$ (\%) & $12(25.0)$ & $60(25.0)$ & 1.000 \\
\hline Smoking, $n$ (\%) & $14(29.2)$ & $42(17.5)$ & 0.062 \\
\hline Coronary artery disease, $n(\%)$ & $18(37.5)$ & $64(26.7)$ & 0.129 \\
\hline Peripheral arterial disease, $n(\%)$ & $6(12.5)$ & $25(10.4)$ & 0.671 \\
\hline Presence of symptom, $n$ (\%) & $37(77.1)$ & $193(80.4)$ & 0.599 \\
\hline
\end{tabular}

Continious variables are presented as mean $\pm S D$, whereas categorical variables are presented as frequency (percentage). 
Yusuf Can, Ibrahim Kocayigit

Table II. Comparison of complication rates between patients with $\mathrm{CCO}$ and without CCO

\begin{tabular}{|c|c|c|c|}
\hline Variable & With CCO & Without CCO & $P$-value \\
\hline 30-day myocardial infarction, $n$ (\%) & $0(0.0)$ & $0(0.0)$ & $* * *$ \\
\hline 6 months myocardial infarction, $n(\%)$ & $0(0.0)$ & $1(0.4)$ & 0.654 \\
\hline 1 year myocardial infarction, $n(\%)$ & $1(2.1)$ & $1(0.4)$ & 0.204 \\
\hline Total death 30 days, $n$ (\%) & $1(2.1)$ & $5(2.1)$ & 1.000 \\
\hline Total death 6 months, $n(\%)$ & $1(2.1)$ & $7(2.9)$ & 0.748 \\
\hline Total death 1 year, $n(\%)$ & $4(8.3)$ & $11(4.6)$ & 0.286 \\
\hline Cardiac death 30 days, $n$ (\%) & $1(2.1)$ & $5(2.1)$ & 1.000 \\
\hline Cardiac death 6 months, $n$ (\%) & $1(2.1)$ & $7(2.9)$ & 0.748 \\
\hline Cardiac death 1 year, $n$ (\%) & $3(6.2)$ & $10(4.2)$ & 0.526 \\
\hline Non-cardiac death 30 days, $n$ (\%) & $0(0.0)$ & $0(0.0)$ & $* * *$ \\
\hline Non-cardiac death 6 months, $n(\%)$ & $0(0.0)$ & $0(0.0)$ & $* * *$ \\
\hline Non-cardiac death 1 year, $n(\%)$ & $1(2.1)$ & $1(0.4)$ & 0.204 \\
\hline Stroke 30 days, $n(\%)$ & $1(2.1)$ & $2(0.8)$ & 0.436 \\
\hline Stroke 6 months, $n$ (\%) & $1(2.1)$ & $3(1.2)$ & 0.652 \\
\hline Stroke 1 year, $n(\%)$ & $1(2.1)$ & $3(1.2)$ & 0.652 \\
\hline TIA 30 days, $n(\%)$ & $0(0.0)$ & $2(0.8)$ & 0.526 \\
\hline TIA 6 months, $n$ (\%) & $0(0.0)$ & $2(0.8)$ & 0.526 \\
\hline TIA 1 year, $n(\%)$ & $0(0.0)$ & $3(1.2)$ & 0.436 \\
\hline Composite outcome 30 days, $n(\%)$ & $2(4.2)$ & $8(3.3)$ & 0.773 \\
\hline Composite outcome 6 months, $n$ (\%) & $2(4.2)$ & $13(5.4)$ & 0.722 \\
\hline Composite outcome 1 year, $n(\%)$ & $6(12.5)$ & $18(7.5)$ & 0.253 \\
\hline
\end{tabular}

Categorical variables are presented as frequency (percentage). TIA - transient ischemic attack, ${ }^{* * *}$ not available.

Nejim et al. found that the outcome of CAS was not superior to that of CEA in patients with asymptomatic CCO during the perioperative period, although the outcome of symptomatic patients was worse [14]. Ricotta et al. observed similar instances of major cardiac events, stroke, death and $\mathrm{MI}$ following surgery and stent placement in patients with CCO undergoing carotid revascularisation [15]. The outcomes of CAS vs. CEA were similar in regard to the absolute risk of periprocedural major adverse cardiovascular events $(2.7 \%$ vs. $4.2 \%)$, mortality ( $1.1 \%$ vs. $0.7 \%)$, stroke $(2.1 \%$ vs. $3.1 \%)$ and $\mathrm{MI}(0.3 \%$ vs. $0.6 \%)$. Texakalidis et al. found that risks of stroke, MI, and major cardiac events were similar for CAS and CEA during the revascularisation in patients with CCO. However, the 30-day periprocedural mortality rate was lower in the surgical branch [16].

Patients with CCO who underwent CAS may have a greater peri-procedural risk of chronic renal failure, heart failure and chronic obstructive pulmonary disease.
Mercado et al. found that the risks of in-hospital mortality, non-fatal MI and non-fatal ischaemic stroke were similar in patients with and without CCO after CAS, as there were no significant differences in composite outcomes (2.1\% vs. $2.6 \%$, $p=0.316)$. Likewise, the risks of mortality $(0.8 \%$ vs. $0.4 \%, p=0.08)$, non-fatal stroke $(1.1 \%$ vs. $1.7 \% p=0.103)$ and non-fatal MI (0.2\% vs. $0.5 \%$, $p=0.217)$ were similar between those with and without CCO [9]. In a study comparing patients with and without CCO who underwent carotid stenting, Keldahl et al. found no significant differences in 30-day mortality (0\% vs. $0.5 \%, p=0.99$ ), stroke (2.6\% vs. $1.9 \%, p=0.55)$ and $\mathrm{MI}(0 \%$ vs. $0.5 \%$, $p=0.8)$. Moreover, the long-term rates of mortality $(25.6 \%$ vs. $22.2 \%, p=0.63)$, stroke (5.3\% vs. $3.4 \%, p=0.64)$ and $\mathrm{MI}(15.4 \%$ vs. $14 \%, p=0.81)$ were also similar [17]. In addition, Lago et al. reported similar 30-day and long-term complication rates between patients with and without CCO after CAS [18]. In the present study, the 30-day, 6-month and 1-year rates of mortality, stroke and 
Table III. Comparison of complication rates in patients over and under 75 years of age

\begin{tabular}{|c|c|c|c|c|c|c|}
\hline \multirow[t]{2}{*}{ Variable } & \multicolumn{3}{|c|}{ Age $<75(n=102)$} & \multicolumn{3}{|c|}{ Age $\geq 75(n=186)$} \\
\hline & $\begin{array}{l}\text { With CCO } \\
(n=16)\end{array}$ & $\begin{array}{c}\text { Without } \\
\text { CCO } \\
(n=86)\end{array}$ & $P$-value & $\begin{array}{l}\text { With CCO } \\
(n=32)\end{array}$ & $\begin{array}{c}\text { Without } \\
\text { CCO } \\
(n=154)\end{array}$ & $P$-value \\
\hline 30-day myocardial infarction, $n$ (\%) & $0(0.0)$ & $0(0.0)$ & $* * *$ & $0(0.0)$ & $0(0.0)$ & $* * *$ \\
\hline 6 months myocardial infarction, $n(\%)$ & $0(0.0)$ & $0(0.0)$ & $* * *$ & $0(0.0)$ & $1(1.2)$ & 0.665 \\
\hline 1 year myocardial infarction, $n(\%)$ & $0(0.0)$ & $0(0.0)$ & $* * *$ & $1(6,2)$ & $1(1.2)$ & 0.178 \\
\hline Total death 30 days, $n$ (\%) & $0(0.0)$ & $1(0.6)$ & 0.648 & $1(6.2)$ & $4(4.6)$ & 0.786 \\
\hline Total death 6 months, $n$ (\%) & $1(3.1)$ & $3(1.9)$ & 0.676 & $0(0.0)$ & $4(4.6)$ & 0.379 \\
\hline Total death 1 year, $n$ (\%) & $2(6.2)$ & $4(2.6)$ & 0.287 & $2(12.5)$ & $7(8.1)$ & 0.572 \\
\hline Cardiac death 30 days, $n$ (\%) & $0(0.0)$ & $1(0.6)$ & 0.648 & $1(6.2)$ & $4(4.6)$ & 0.786 \\
\hline Cardiac death 6 months, $n$ (\%) & $1(3.1)$ & $3(1.9)$ & 0.676 & $0(0.0)$ & $4(4.6)$ & 0.379 \\
\hline Cardiac death 1 year, $n$ (\%) & $2(6.2)$ & $3(1.9)$ & 0.171 & $1(6.2)$ & $7(8.1)$ & 0.796 \\
\hline Non-cardiac death 30 days, $n$ (\%) & $0(0.0)$ & $0(0.0)$ & $* * *$ & $0(0.0)$ & $0(0.0)$ & $* * *$ \\
\hline Non-cardiac death 6 months, $n$ (\%) & $0(0.0)$ & $0(0.0)$ & $* * *$ & $0(0.0)$ & $0(0.0)$ & $* * *$ \\
\hline Non-cardiac death 1 year, $n$ (\%) & $0(0.0)$ & $1(0.6)$ & 0.648 & $1(6.2)$ & $0(0.0)$ & 0.020 \\
\hline Stroke 30 days, $n$ (\%) & $1(3.1)$ & $0(0.0)$ & 0.028 & $0(0.0)$ & $2(2.3)$ & 0.538 \\
\hline Stroke 6 months, $n(\%)$ & $1(3.1)$ & $0(0.0)$ & 0.028 & $0(0.0)$ & $3(3.5)$ & 0.448 \\
\hline Stroke 1 year, $n$ (\%) & $1(3.1)$ & $0(0.0)$ & 0.028 & $0(0.0)$ & $3(3.5)$ & 0.448 \\
\hline TIA 30 days, $n(\%)$ & $0(0.0)$ & $2(1.3)$ & 0.517 & $0(0.0)$ & $0(0.0)$ & $* * *$ \\
\hline TIA 6 months, $n$ (\%) & $0(0.0)$ & $2(1.3)$ & 0.517 & $0(0.0)$ & $0(0.0)$ & $* * *$ \\
\hline TIA 1 year, $n(\%)$ & $0(0.0)$ & $3(1.9)$ & 0.426 & $0(0.0)$ & $0(0.0)$ & $* * *$ \\
\hline Composite outcome 30 days, $n(\%)$ & $1(3.1)$ & $3(1.9)$ & 0.676 & $1(6.2)$ & $5(5.8)$ & 0.946 \\
\hline Composite outcome 6 months, $n$ (\%) & $2(6.2)$ & $5(3.2)$ & 0.417 & $0(0.0)$ & $8(9.3)$ & 0.204 \\
\hline Composite outcome 1 year, $n$ (\%) & $3(9.4)$ & $7(4.5)$ & 0.270 & $3(18.7)$ & $11(12.8)$ & 0.525 \\
\hline
\end{tabular}

MI were similar between patients with and without CCO after CAS.

Previous studies comparing patients aged $<75$ vs. $\geq 75$ years who underwent CAS showed that the risks of procedural stroke and mortality were higher in older patients [19-21]. Guo et al. observed greater risks of stroke, MI, and mortality in patients aged $>75$ vs. $<75$ years with and without CCO after CAS [22]. In the present study, the risk of stroke was greater in those aged $<75$ years, whereas the risk of non-cardiac mortality was greater in those aged $>75$ years, while the 1-year composite outcome was similar between patients aged $<75$ and $\geq 75$ years.

Mercado et al. compared symptomatic and asymptomatic patients with and without CCO who underwent CCO. Mercado et al. found no difference in composite outcomes between symptomatic and asymptomatic patients with or without CCO (3.4\% vs. $3.5 \%$, respectively, $p=0.956$ ) [9].
Similarly, in the present study, the clinical outcomes were similar between symptomatic and asymptomatic patients.

The most important restriction of our study was that it was a single-centred retrospective study. The other major restriction was that we were unable to compare patients who underwent CAS to those who underwent CEA.

In conclusion, no difference was found in terms of stroke, MI, or mortality between patients with and without CCO after CAS. We demonstrated that CAS is a safe and effective revascularisation strategy in patients with CCO. The outcomes were similar in terms of age and symptoms. However, these data should be verified in prospective multicentre studies.

\section{Conflict of interest}

The authors declare no conflict of interest. 
Table IV. Comparison of complication rates of those with and without symptoms

\begin{tabular}{|c|c|c|c|c|c|c|}
\hline \multirow[t]{2}{*}{ Variable } & \multicolumn{3}{|c|}{ Symptomatic $(n=230)$} & \multicolumn{3}{|c|}{ Asymptomatic $(n=58)$} \\
\hline & $\begin{array}{l}\text { With CCO } \\
(n=37)\end{array}$ & $\begin{array}{l}\text { Without } \\
\text { CCO } \\
(n=193)\end{array}$ & $P$-value & $\begin{array}{l}\text { With CCO } \\
(n=11)\end{array}$ & $\begin{array}{l}\text { Without } \\
\text { CCO } \\
(n=47)\end{array}$ & $P$-value \\
\hline 30-day myocardial infarction, $n$ (\%) & $0(0.0)$ & $0(0.0)$ & $* * *$ & $0(0.0)$ & $0(0.0)$ & *** \\
\hline 6 months myocardial infarction, $n(\%)$ & $0(0.0)$ & $1(0.5)$ & 0.661 & $0(0.0)$ & $0(0.0)$ & *** \\
\hline 1 year myocardial infarction, $n(\%)$ & $1(2.7)$ & $1(0.5)$ & 0.090 & $0(0.0)$ & $0(0.0)$ & *** \\
\hline Total death 30 days, $n$ (\%) & $1(2.7)$ & $5(2.6)$ & 0.969 & $0(0.0)$ & $0(0.0)$ & *** \\
\hline Total death 6 months, $n(\%)$ & $1(2.7)$ & $6(3.1)$ & 0.895 & $0(0.0)$ & $1(2.1)$ & 0.626 \\
\hline Total death 1 year, $n(\%)$ & $4(10.8)$ & $10(5.2)$ & 0.190 & $0(0.0)$ & $1(2.1)$ & 0.626 \\
\hline Cardiac death 30 days, $n$ (\%) & $1(2.7)$ & $5(2.6)$ & 0.969 & $0(0.0)$ & $0(0.0)$ & $* * *$ \\
\hline Cardiac death 6 months, $n(\%)$ & $1(2.7)$ & $6(3.1)$ & 0.895 & $0(0.0)$ & $1(2.1)$ & 0.626 \\
\hline Cardiac death 1 year, $n(\%)$ & $3(8.1)$ & $9(4.7)$ & 0.388 & $0(0.0)$ & $1(2.1)$ & 0.626 \\
\hline Non-cardiac death 30 days, $n$ (\%) & $0(0.0)$ & $0(0.0)$ & $* * *$ & $0(0.0)$ & $0(0.0)$ & *** \\
\hline Non-cardiac death 6 months (n, \%) & $0(0.0)$ & $0(0.0)$ & $* * *$ & $0(0.0)$ & $0(0.0)$ & *** \\
\hline Non-cardiac death 1 year, $n(\%)$ & $1(2.7)$ & $1(0.5)$ & 0.190 & $0(0.0)$ & $0(0.0)$ & *** \\
\hline Stroke 30 days, $n(\%)$ & $1(2.7)$ & $2(1.0)$ & 0.413 & $0(0.0)$ & $0(0.0)$ & *** \\
\hline Stroke 6 months, $n$ (\%) & $1(2.7)$ & $3(1.5)$ & 0.625 & $0(0.0)$ & $0(0.0)$ & *** \\
\hline Stroke 1 year, $n(\%)$ & $1(2.7)$ & $3(1.5)$ & 0.625 & $0(0.0)$ & $0(0.0)$ & *** \\
\hline TIA 30 days, $n(\%)$ & $0(0.0)$ & $2(1.0)$ & 0.534 & $0(0.0)$ & $0(0.0)$ & $* * *$ \\
\hline TIA 6 months, $n$ (\%) & $0(0.0)$ & $2(1.0)$ & 0.534 & $0(0.0)$ & $0(0.0)$ & *** \\
\hline TIA 1 year, $n(\%)$ & $0(0.0)$ & $3(1.5)$ & 0.445 & $0(0.0)$ & $0(0.0)$ & $* * *$ \\
\hline Composite outcome 30 days, $n$ (\%) & $2(5.4)$ & $8(4.1)$ & 0.731 & $0(0.0)$ & $0(0.0)$ & $* * *$ \\
\hline Composite outcome 6 months, $n$ (\%) & $2(5.4)$ & $12(6.2)$ & 0.850 & $0(0.0)$ & $1(2.1)$ & 0.626 \\
\hline Composite outcome 1 year, $n(\%)$ & $6(16.2)$ & $17(8.8)$ & 0.169 & $0(0.0)$ & $1(2.1)$ & 0.626 \\
\hline
\end{tabular}

Categorical variables are presented as frequency (percentage). TIA - transient ischemic attack, ${ }^{* * *}$ not available.

\section{References}

1. Moresoli P, Habib B, Reynier P, et al. Carotid stenting versus endarterectomy for asymptomatic carotid artery stenosis: a systematic review and meta-analysis. Stroke 2017; 48: 2150-7.

2. Brott TG, Halperin JL, Abbara S, et al. 2011 guideline on the management of patients with extracranial carotid and vertebral artery disease. Stroke 2011; 42: e464-540.

3. Kempczinski RF. The chronically ischemic leg: an overwiew. In: Vascular Surgery. 5th edn. Rutherford RB (ed.). WB Saunders Co. 2000; 917-27.

4. Dumont TM, Rughani Al. National trends in carotid artery revascularization surgery. J Neurosurg 2012; 116: 1251-7.

5. Lloyd-Jones D, Adams R, Carnethon M, et al. Heart disease and stroke statistics - 2009 update: a report from the American Heart Association Statistics Committee and Stroke Statistics Subcommittee. Circulation 2009; 119: 480-6.

6. Gasecki AP, Eliasziw M, Ferguson GG, Hachinski V, Barnett HJ. Long-term prognosis and effect of endarterectomy in patients with symptomatic severe carotid ste- nosis and contralateral carotid stenosis or occlusion: results from NASCET. North American Symptomatic Carotid Endarterectomy Trial (NASCET) Group. J Neurosurg 1995; 83: 778-82.

7. Baker WH, Howard VJ, Howard G, Toole JF. Effect of contralateral occlusion on long-term efficacy of endarterectomy in the asymptomatic carotid atherosclerosis study (ACAS). ACAS Investigators. Stroke 2000; 31: 2330-4.

8. Brott TG, Halperin JL, Abbara S, et al. 2011 ASA/ACCF/ AHA/AANN/AANS/ACR/ASNR/CNS/SAIP/SCAI/SIR/ SNIS/SVM/SVS Guideline on the Management of Patients With Extracranial Carotid and Vertebral Artery Disease: Executive Summary A Report of the American College of Cardiology Foundation/American Heart Association Task Force on Practice Guidelines, and the American Stroke Association, American Association of Neuroscience Nurses, American Association of Neurological Surgeons, American College of Radiology, American Society of Neuroradiology, Congress of Neurological Surgeons, Society of Atherosclerosis Imaging and Prevention, Society for Cardiovascular Angiography and Interventions, Society of Interventional Radiology, Soci- 
ety of Neurolnterventional Surgery, Society for Vascular Medicine, and Society for Vascular Surgery Developed in Collaboration With the American Academy of Neurology and Society of Cardiovascular Computed Tomography. J Am Coll Cardiol 2011; 57: 1002-44.

9. Mercado N, Cohen D, Spertus J, et al. Carotid artery stenting of a contralateral occlusion and in-hospital outcomes: results from the CARE (Carotid Artery Revascularization and Endarterectomy) registry. JACC Cardiovasc Interv 2013; 6: 59-64.

10. Hammacher ER, Eikelboom BC, Bast TJ, et al. Surgical treatment of patients with a carotid artery occlusion and a contralateral stenosis. J Cardiovasc Surg 1984; 25: 513-7.

11. Rockman CB, Su W, Lamparello PJ, et al. A reassessment of carotid endarterectomy in the face of contralateral carotid occlusion: surgical results in symptomatic and asymptomatic patients. J Vasc Surg 2002; 36: 668-73.

12. Goodney PP, Likosky DS, Cronenwett JL. Factors associated with stroke or death after carotid endarterectomy in Northern New England. J Vasc Surg 2008; 48: 1139-45.

13. Maatz W, Köhler J, Botsios S, et al. Risk of stroke for carotid endarterectomy patients with contralateral carotid occlusion. Ann Vasc Surg 2008; 22: 45-51.

14. Nejim B, Dakour Aridi H, Locham S, et al. Carotid artery revascularization in patients with contralateral carotid artery occlusion: stent or endarterectomy? J Vasc Surg 2017; 66: 1735-48.

15. Ricotta JJ 2nd, Upchurch GR Jr, et al. The influence of contralateral occlusion on results of carotid interventions from the Society for Vascular Surgery Vascular Registry. J Vasc Surg 2014; 60: 958-64.

16. Texakalidis P, Giannopoulos S, Damianos G, et al. Carotid artery endarterectomy versus carotid artery stenting for patients with contralateral carotid occlusion: a systematic review and meta-analysis. World Neurosurg 2018; 120: 563-71.

17. Keldahl ML, Park MS, Garcia-Toca M, et al. Does a contralateral carotid occlusion adversely impact carotid artery stenting outcomes? Ann Vasc Surg 2012; 26: 40-5.

18. Lago A, Parkhutik V, Tembl Jl, et al. Long-term outcome in patients with carotid artery stenting and contralateral carotid occlusion: a single neurovascular center prospective analysis. Neuroradiology 2012; 54: 965-72.

19. Touzé E, Trinquart L, Felgueiras R, et al. A clinical rule (sex, contralateral occlusion, age, and restenosis) to select patients for stenting versus carotid endarterectomy: systematic review of observational studies with validation in randomized trials. Stroke 2013; 44: 3394-400.

20. Ahmadi R, Schillinger M, Lang W, et al. Carotid artery stenting in older patients: is age a risk factor for poor outcome? J Endovasc Ther 2002; 9: 559-65.

21. Voeks J, Howard G, Roubin G, et al. Age and outcomes after carotid stenting and endarterectomy: the carotid revascularization endarterectomy versus stenting trial. Stroke 2011; 42: 3484-90.

22. Guo J, Guo L, Tong Z, et al, Three-year clinical results of carotid artery stenting in treating patients with contralateral carotid artery occlusion. J Stroke Cerebrovasc Dis 2018; 27: 1296-301. 